\title{
Systematic analysis of overall survival and interactions between tumor mutations and drug treatment
}

\author{
Francesco Gatto and Jens Nielsen*
}

\begin{abstract}
Background: Few exceptional responses in cancer treatment were attributed to a genetic predisposition of the tumor.

Methods: We analyzed a cohort of 3105 patients from 12 different cancer types and systematically sought the existence of a correlation between overall survival and the interaction of 21 antineoplastic treatments with 6 tumor mutations.

Results: We identified a single significant correlation resulting in increased overall survival from temozolomide in lower-grade glioma with IDH1 R132H mutations. The trend could not be attributed to either the treatment or the mutation alone. Univariate and multivariate Cox regression demonstrated that this interaction stood as an independent prognostic predictor of survival.

Conclusion: Our results suggest infrequent instances of exceptional responses ascribable to tumor genomics yet corroborate the existence of an interaction of temozolomide with IDH1 mutations in lower-grade glioma.
\end{abstract}

Keywords: Cancer genomics, Exceptional response, Large-scale data analysis, Systems biology, Lower-grade glioma

\section{Findings}

The cancer genome can elicit sensitivity to certain drugs not specifically designed to target the underlying genetic aberrations. To this end, genomic markers of drug sensitivity have been systematically assessed in cancer cell lines [1,2]. Ideally, these markers can identify patients who may better benefit from a certain antineoplastic drug [3, 4]. In contrast to the increasing availability of data about genomics of drug sensitivity in vitro [5], the association with improved patient survival is so far limited to few clinical cases, e.g., exceptional responses to everolimus in bladder cancers with TSC1 mutations [6].

Here, we sought to systematically assess if the chances of overall survival in patients with a certain cancer type and treated with a given antineoplastic

\footnotetext{
*Correspondence: nielsenj@chalmers.se

Department of Biology and Biological Engineering, Chalmers University of Technology, Göteborg 41296, Sweden
}

(c) 2016 Gatto and Nielsen. Open Access This article is distributed under the terms of the Creative Commons Attribution 4.0 International License (http://creativecommons.org/licenses/by/4.0/), which permits unrestricted use, distribution, and reproduction in any medium, provided you give appropriate credit to the original author(s) and the source, provide a link to the Creative Commons license, and indicate if changes were made. The Creative Commons Public Domain Dedication waiver (http://creativecommons.org/publicdomain/zero/1.0/) applies to the data made available in this article, unless otherwise stated.

drug correlate with the presence of a certain genetic mutation in the tumor. The examined cohort comprised 3105 patients, spanning 12 cancer types (with 81-731 samples for each cancer type). Collectively, 21 antineoplastic drugs were administered each in at least 20 patients (median 82; IQR 29-150). Six cancer-associated mutations were detected in at least 20 patients in this cohort: V600E in BRAF $(n=29)$, $\mathrm{R} 132 \mathrm{H}$ in IDH1 $(n=108), \mathrm{G} 12 \mathrm{~V}$ in KRAS $(n=49)$, H1047R in PIK3CA $(n=89), \mathrm{R} 175 \mathrm{H}$ in TP53 $(n=45)$, and V777 deletion in ZFHX3 $(n=22)$. After binning samples by cancer type, out of 1512 potential associations, 9 associations between overall survival, drug treatment, and tumor mutation had sufficient sample size for each covariate and were hereby tested. The hazard ratio (HR) for each interaction between drug treatment and tumor mutation in a cancer type was estimated in a multivariate analysis using a nested Cox proportional hazard regression model. We 
adopted a likelihood ratio test to test whether there is a significant effect of the interaction on overall survival on top of the tumor mutation and administered drug alone (Additional file 1: Table S1).

We observed a significant effect only in one scenario, the interaction between temozolomide (TMZ) and $\mathrm{R} 132 \mathrm{H}$ mutations in IDH1 on the overall survival of lower-grade glioma (LGG) (likelihood ratio test $p=$ 0.026). This test suggests that the correlation with survival is specific to the interaction between TMZ and $\mathrm{R} 132 \mathrm{H}$ mutations in $I D H 1$ and not associated with the drug treatment or the mutation per se, as demonstrated by the Kaplan-Meier curves generated for patients stratified upon these features (log-rank test $p=0.047$, Fig. 1). The median overall survival for patients with the interaction was 95 months (95\% CI, 63-N.E.) and for patients without the interaction was 62 months (95\% CI, 49-87).

We detected a significant prognostic value for the interaction using a univariate Cox proportional hazard regression model $(p=0.016$, Table 1$)$. However, the interaction violated the proportional hazard assumption and showed a time-dependent effect. The univariate analysis was also run on validated prognostic factors in LGG [7] and additional clinical features (Table 1). A multivariate analysis based on significant factors from the univariate analysis and including a time-dependent effect for the interaction revealed an independent positive correlation between the interaction and overall survival (HR 0.09, $95 \%$ CI 0.01-0.58, $p=0.012$ ), which tends to diminish over time (Additional file 1: Figure S1).

In conclusion, we identified one genomic marker of drug sensitivity that was associated with better survival in patients, in contrast to patients treated with the same drug but with no detected mutation or vice versa. Indeed, mutations in IDH1 were previously implicated with good prognosis in brain tumors treated with $\operatorname{TMZ}[8,9]$. Our results independently validate these findings and further extend the reach of this correlation beyond some previous limitations [10]. First and foremost, the cohort size allowed discerning that an increase in patient survival was exquisitely associated with the interaction between $I D H 1$ mutations and TMZ, suggestive of a synergy between

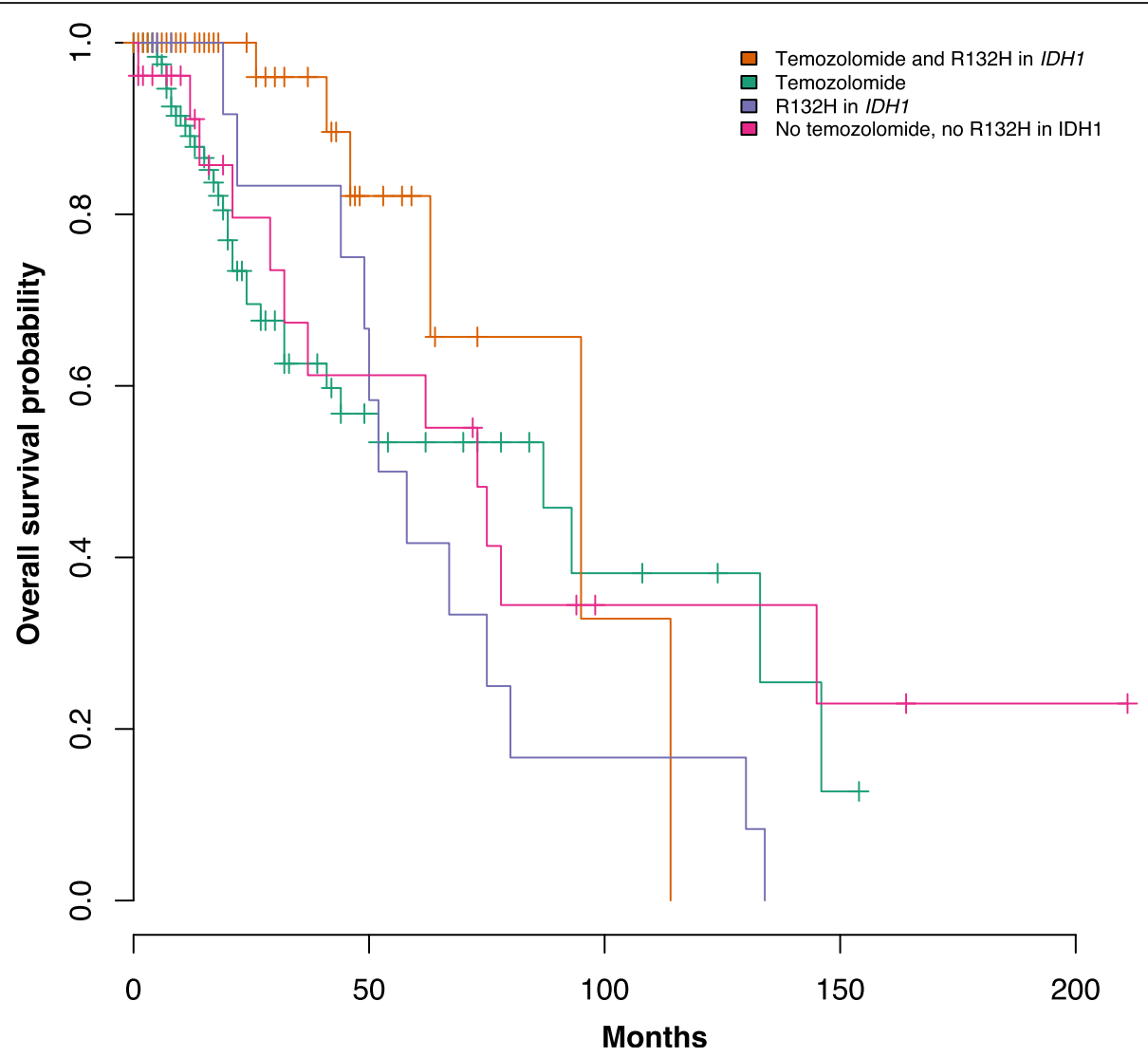

Fig. 1 Kaplan-Meier survival plots for patients with or without an interaction between temozolomide and R132H mutations in IDH1 in lower-grade glioma 
Table 1 Hazard ratio (HR) for clinical factors in the overall survival of lower-grade glioma

\begin{tabular}{|c|c|c|c|c|c|c|c|}
\hline \multirow[t]{2}{*}{ Factors } & \multirow{2}{*}{$\begin{array}{l}N \\
{[n \text { death }]}\end{array}$} & \multirow[t]{2}{*}{$\mathrm{HR}$} & \multicolumn{2}{|l|}{ Univariate } & \multicolumn{3}{|c|}{ Multivariate } \\
\hline & & & $95 \% \mathrm{Cl}$ & $p$ & $\mathrm{HR}$ & $95 \% \mathrm{Cl}$ & p \\
\hline Age & 261 & 1.07 & $1.05-1.09$ & $5 e^{-10}$ & 1.07 & $1.05-1.09$ & $6 e^{-9}$ \\
\hline \multicolumn{8}{|l|}{ Gender } \\
\hline Female & $117[30]$ & 1 & & & & & \\
\hline Male & 144 [33] & 0.88 & $0.54-1.45$ & 0.620 & & & \\
\hline \multicolumn{8}{|l|}{ Temozolomide } \\
\hline No & $41[24]$ & 1 & & & & & \\
\hline Yes & 220 [39] & 0.80 & $0.47-1.35$ & 0.398 & & & \\
\hline \multicolumn{8}{|l|}{$\mathrm{R} 132 \mathrm{H}$ in $\mathrm{IDH} 1$} \\
\hline Undetected & $166[45]$ & 1 & & & & & \\
\hline Detected & $95[18]$ & 0.74 & $0.43-1.29$ & 0.292 & & & \\
\hline \multicolumn{8}{|l|}{ Interaction drug-mutation } \\
\hline Absent & $181[57]$ & 1 & & & 1 & & \\
\hline Present & $80[6]$ & 0.35 & $0.15-0.83$ & 0.016 & 0.09 & $0.01-0.58$ & 0.012 \\
\hline \multicolumn{8}{|l|}{ Histology } \\
\hline Astrocytoma & 107 [27] & 1 & & & & & \\
\hline $\begin{array}{l}\text { Oligoastrocytoma/ } \\
\text { oligodendroglioma }\end{array}$ & 154 [36] & 0.67 & $0.40-1.10$ & 0.112 & & & \\
\hline \multicolumn{8}{|l|}{ Tumor grade } \\
\hline Grade II & $77[18]$ & 1 & & & 1 & & \\
\hline Grade III & $184[45]$ & 2.06 & $1.18-3.61$ & 0.011 & 1.52 & $0.85-2.71$ & 0.159 \\
\hline \multicolumn{8}{|l|}{ Laterality } \\
\hline N.A. & 1 & & & & & & \\
\hline Left & $131[28]$ & 1 & & & & & \\
\hline Midline & $5[1]$ & 0.34 & $0.04-2.64$ & 0.304 & & & \\
\hline Right & $123[33]$ & 0.82 & $0.49-1.37$ & 0.443 & & & \\
\hline \multicolumn{8}{|l|}{ Tumor site } \\
\hline N.A./other & 3 & & & & 1 & & \\
\hline Supratentorial, frontal lobe & $160[36]$ & 1 & & & & & \\
\hline Supratentorial, occipital lobe & $5[1]$ & 0.71 & $0.10-5.20$ & 0.736 & & & \\
\hline Supratentorial, parietal lobe & $23[4]$ & 0.84 & $0.30-2.38$ & 0.748 & & & \\
\hline Supratentorial, temporal lobe & $70[21]$ & 1.86 & $1.08-3.22$ & 0.026 & 1.22 & $0.70-2.11$ & 0.481 \\
\hline \multicolumn{8}{|l|}{ Symptoms at diagnosis } \\
\hline N.A./other & 19 & & & & & & \\
\hline Headaches & $62[18]$ & 1 & & & & & \\
\hline Mental status changes & $22[8]$ & 1.84 & $0.80-4.27$ & 0.153 & & & \\
\hline Motor/movement changes & $22[6]$ & 1.20 & $0.47-3.06$ & 0.698 & & & \\
\hline Seizures & 119 [23] & 0.58 & $0.31-1.08$ & 0.087 & & & \\
\hline Sensory changes & $11[2]$ & 1.07 & $0.24-4.66$ & 0.929 & & & \\
\hline Visual changes & $6[2]$ & 0.69 & $0.16-2.98$ & 0.617 & & & \\
\hline
\end{tabular}

treatment and tumor genomics. Second, it specifically correlated with $\mathrm{R} 132 \mathrm{H}$ mutations. Finally, we recovered a negative time-dependent effect of the interaction, which is reminiscent of emergence of drug resistance and in line with the genetic evolution of lower-grade glioma attributed to TMZ treatment [11]. 


\section{Additional file}

Additional file 1: Supplemental methods, figures, and tables. (PDF $138 \mathrm{~kb}$ )

Competing interests

The authors declare no conflict of interest in relation to the submitted work.

\section{Authors' contributions}

FG conceived and designed the study and performed the analyses; JN supervised the study. All authors approved the manuscript in its final form.

\section{Acknowledgements}

The authors acknowledge Knut and Alice Wallenberg Foundation for financing this work.

Received: 28 January 2016 Accepted: 24 February 2016

Published online: 02 March 2016

\section{References}

1. Barretina J, Caponigro G, Stransky N, Venkatesan K, Margolin AA, Kim S, et al. The Cancer Cell Line Encyclopedia enables predictive modelling of anticancer drug sensitivity (vol 483, pg 603, 2012). Nature. 2012;492:290.

2. Garnett MJ, Edelman EJ, Heidorn SJ, Greenman CD, Dastur A, Lau KW, et al. (2012). Systematic identification of genomic markers of drug sensitivity in cancer cells. Nature 483, 570-U587.X

3. Garraway LA, Lander ES. Lessons from the cancer genome. Cell. 2013;153: $17-37$.

4. Stratton M, Garnett M, Edelman EJ, Heidorn S, Futreal PA, Haber D, et al. The genomics of drug sensitivity in cancer. European Journal of Cancer. 2012;48:S8.

5. Yang WJ, Soares J, Greninger P, Edelman EJ, Lightfoot H, Forbes S, et al. Genomics of drug sensitivity in cancer (GDSC): a resource for therapeutic biomarker discovery in cancer cells. Nucleic acids research. 2013;41:D955-61.

6. Iyer G, Hanrahan AJ, Milowsky MI, Al-Ahmadie H, Scott SN, Janakiraman M, et al. Genome sequencing identifies a basis for everolimus sensitivity. Science. 2012;338:221.

7. Pignatti F, van den Bent M, Curran D, Debruyne C, Sylvester R, Therasse P, et al. Prognostic factors for survival in adult patients with cerebral low-grade glioma. Journal of clinical oncology : official journal of the American Society of Clinical Oncology. 2002;20:2076-84.

8. Houillier C, Wang X, Kaloshi G, Mokhtari K, Guillevin R, Laffaire J, et al. IDH1 or IDH2 mutations predict longer survival and response to temozolomide in low-grade gliomas. Neurology. 2010;75:1560-6.

9. Kong DS, Kim HR, Choi YR, Seol HJ, Lee Jl, Nam DH. Prognostic impact of molecular phenotype in patients with recurrent anaplastic glioma treated with prolonged administration of temozolomide. Journal of clinical neuroscience : official journal of the Neurosurgical Society of Australasia. 2015;22:1425-9.

10. Dubbink HJ, Taal W, van Marion R, Kros JM, van Heuvel I, Bromberg JE, et al. $\mathrm{IDH} 1$ mutations in low-grade astrocytomas predict survival but not response to temozolomide. Neurology. 2009:73:1792-5.

11. Johnson BE, Mazor T, Hong C, Barnes M, Aihara K, McLean CY, et al. Mutational analysis reveals the origin and therapy-driven evolution of recurrent glioma. Science. 2014:343:189-93.

\section{Submit your next manuscript to BioMed Central} and we will help you at every step:

- We accept pre-submission inquiries

- Our selector tool helps you to find the most relevant journal

- We provide round the clock customer support

- Convenient online submission

- Thorough peer review

- Inclusion in PubMed and all major indexing services

- Maximum visibility for your research

Submit your manuscript at www.biomedcentral.com/submit 